\title{
Correction to: The COVID-19 Pandemic and its Impact on the Cardio-Oncology Population
}

\author{
Ishan Asokan ${ }^{1}$ - Soniya V. Rabadia ${ }^{1}$ - Eric H. Yang ${ }^{2,3}$ \\ Published online: 11 July 2020 \\ (C) Springer Science+Business Media, LLC, part of Springer Nature 2020
}

\section{Correction to: Curr Oncol Rep (2020) 22:60 https://doi.org/10.1007/s11912-020-00945-4}

In light of the recent retraction of the New England Journal of Medicine article entitled "Cardiovascular Disease, Drug Therapy, and Mortality in COVID-19" (Mehra et al., full citation provided below), the authors would like to remove the following statement, which appeared on page 2, under the heading Cardiovascular Disease and COVID-19:

"An observational database of the Surgical Outcomes Collaborative registry, which comprised of 8910 hospitalized COVID-19 patients from 169 hospitals in Asia, Europe, and North America, found that an age greater than 65, and diagnosis of history coronary artery disease, heart failure, and/or cardiac arrhythmias were independently associated with increased risk of in-hospital death, with 5.8\% $(n=515)$ of this cohort dying in the hospital [17]."

Given the existence of other epidemiological studies cited in this review, the authors believe the removal of this statement does not significantly alter the impact and objectives of this article.

Citation:

Mehra MR, Desai SS, Kuy S, Henry TD, Patel AN. Retraction: Cardiovascular Disease, Drug Therapy, and Mortality in COVID-19. N Engl J Med 2020; DOI: https:// doi.org/10.1056/NEJMc2021225.

Publisher's Note Springer Nature remains neutral with regard to jurisdictional claims in published maps and institutional affiliations.

The online version of the original article can be found at https://doi.org/ 10.1007/s11912-020-00945-4

Eric H. Yang

ehyang@mednet.ucla.edu

1 Department of Medicine, UCLA Medical Center, Los Angeles, CA, USA

2 UCLA Cardio-Oncology Program, Division of Cardiology, Department of Medicine, UCLA Medical Center, Los Angeles, CA, USA

3 UCLA Cardiovascular Center, 100 Medical Plaza, Suite 630, Los Angeles, CA 90095, USA 